\title{
Dietary total antioxidant capacity and the risk of breast cancer: a case-control study
}

\author{
Z. Karimi, ${ }^{1}$ Z. Bahadoran, ${ }^{2}$ S.Abedini, ${ }^{1}$ A. Houshyar-Rad ${ }^{7}$ and B. Rashidkhani ${ }^{3}$
}



ABSTRACT There is growing evidence that dietary antioxidants may have favourable effects in reducing cancer risk. In a case-control study we investigated the association of dietary total antioxidant capacity (TAC) and risk of breast cancer. Sociodemographic data, medical history and anthropometric measurements were collected from 275 women (100 breast cancer cases \& 175 controls). Participants' usual dietary intake was measured using a validated semi-quantitative food frequency questionnaire and their dietary TAC was estimated. An inverse, but non-significant, association was observed between dietary TAC and breast cancer risk. Multiple logistic regression models based on TAC of individual food groups showed that consumption of fruits and vegetables with higher TAC ( $\mu$ molTE/100 g) was associated with a significantly decreased risk of breast cancer. Our study supports a protective effect of dietary antioxidants in relation to breast cancer risk. Food selection based on TAC of foods may be an effective strategy to modify the risk of cancer.

\section{Capacité antioxydante totale de l'alimentation et risque de cancer du sein : étude cas-témoins}

RÉSUMÉ Des données de plus en plus nombreuses indiquent que les antioxydants alimentaires ont des effets favorables sur la réduction du risque de cancer. Dans une étude cas-témoins, nous avons étudié l'association entre la capacité antioxydante totale de l'alimentaire et le risque de cancer du sein. Les données sociodémographiques, les antécédents médicaux et les mesures anthropométriques ont été recueillis auprès de 275 femmes (100 cas de cancer du sein et 175 cas témoins). L'apport alimentaire habituel des participantes a été mesuré à l'aide d'un questionnaire semi-quantitatif validé sur la fréquence de consommation de l'alimentaire, puis la capacité antioxydante totale de l'alimentaire a été estimée. Une association inverse, mais non significative, a été observée entre la capacité antioxydante totale de l'alimentaire et le risque de cancer du sein. Des modèles de régression logistique multiple reposant sur la capacité antioxydante totale des groupes d'aliments individuels ont démontré que la consommation de fruits et de légumes ayant une capacité antioxydante totale plus élevée ( $\mu \mathrm{molTE} / 100 \mathrm{~g}$ ) était associée à un risque significativement moindre de cancer du sein. Notre étude confirme l'effet protecteur des antioxydants alimentaires contre le risque de cancer du sein. La sélection des aliments à partir de leur capacité antioxydante totale peut être une stratégie efficace pour modifier le risque de cancer.

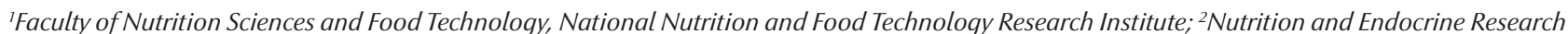
Centre and Obesity Research Centre, Research Institute for Endocrine Sciences; ${ }^{3}$ Department of Community Nutrition, National Nutrition and Food Technology Research Institute, Faculty of Nutrition Sciences and Food Technology, Shahid Beheshti University of Medical Sciences, Tehran, Islamic Republic of Iran (Correspondence to B. Rashidkhani: b_rashidkhani@sbmu.ac.ir).

Received: 02/05/14; accepted: 16/12/14 


\section{Introduction}

Breast cancer is the most common cancer among women in both developed and developing countries and annually more than 1 million new cases are diagnosed worldwide $(1,2)$. In Iranian women breast cancer also is the most common cancer, with an incidence of 22 per 100000 (3). The known risk factors contributing to breast cancer include not only genetic factors, family history and reproductive factors but also potentially modifiable diet-related factors such as body mass index (BMI) and lifestyle, eating patterns and dietary intakes (4-7).

Dietary antioxidants have been reported to protect against oxidative damage and related chronic disease $(8,9)$, but the preventive effects of dietary antioxidants on the risk of breast cancer have not been clarified and the results of epidemiological studies in this regard are limited and inconsistent $(10,11)$. Since the evaluation of a single antioxidant component may not reflect the total antioxidant power of diets and other possible interactions or synergetic effects of antioxidants, the concept of dietary total antioxidant capacity (TAC) was recently developed as a novel and relevant tool for assessment of the beneficial effects of dietary antioxidants $(12,13)$. The TAC of foods describes the ability of food antioxidants to scavenge free radicals and is measured using oxygen radical absorbance capacity assay (14). Dietary TAC has been positively associated with plasma TAC and has also been related to higher diet quality, based on common indexes such as the so-called Mediterranean diet and healthy eating index scores $(13,15)$. Previously we reported that dietary TAC was related to all aspect of the metabolic syndrome and, more interestingly, higher dietary TAC could prevent subsequent weight and abdominal fat gain in adults (16). In the current study, we aimed to study whether dietary TAC was associated with a risk of breast cancer in women.

\section{Methods}

\section{Study design and population}

This was a hospital-based, case-control study conducted among Iranian women. A sample of 100 women with a primary diagnosis of breast cancer were recruited consecutively from January to July 2010 and were frequency-matched to 175 controls by age (5-year intervals). Cases with histologically confirmed breast cancer (maximum duration of 5 months from diagnosis to interview) were recruited from among women aged 30-65 years who referred to the oncology, radiotherapy, chemotherapy or surgery departments of Shohadae-Tajrish hospital in Tehran, Islamic Republic of Iran. Participants with a history of any cancer or cyst (excluding current breast cancer) and a history of hormone therapy or special diets were excluded from the study. Age-matched controls without any history of cancers or cysts, acute or chronic diseases affecting nutritional status or hormone therapy or special diet were recruited from among individuals referring to outpatient clinics of the hospital, including the departments of gynaecology and dermatology, from April to July 2010.

Written informed consent was obtained from all participants and the study protocol was approved by the research council of the Research Institute for Nutrition and Food Sciences, Shahid Beheshti University of Medical Sciences.

\section{Sociodemographic, anthropometrics and physical activity}

Trained interviewers collected data regarding sociodemographic factors including age, educational level, occupation, ethnic group, residential area, alcohol and tobacco use, medical history of disease, family history of breast cancer or other cancers, history of hormone therapy, medications and supplements, oral contraceptives, age at menarche, marital status, number of full-term pregnancies, menopause status and other lifestyle-related factors. Weight was measured to the nearest $100 \mathrm{~g}$ using digital scales, while the subjects were minimally clothed without shoes; height was measured to the nearest $0.5 \mathrm{~cm}$ using a tape meter, with subjects in a standing position without shoes. BMI was calculated as weight $(\mathrm{kg})$ divided by square of the height $\left(\mathrm{m}^{2}\right)$. Physical activity level was assessed using a validated questionnaire to obtain the frequency and time spent on light, moderate, vigorous and very vigorous intensity activities according to the list of common activities of daily life over the previous year. Physical activitylevels were expressed as metabolic equivalent hours per week (METs h/ week) (17).

\section{Dietary assessment}

A validated semi-quantitative food frequency questionnaire (FFQ) with 168 food items was used to estimate the usual dietary intake of participants during the past year. The validity and reliability of this FFQ, developed for dietary assessment of participants in the Tehran Lipid and Glucose Study, was previously assessed in a random sample, by comparing both the data from 2 FFQs completed 1 year apart and the data from the FFQs and 12 dietary recalls respectively (18). The mean energy-adjusted correlation coefficients for overall nutrient intake between the dietary recall and the second FFQwere 0.44 and 0.37 in participants aged $\leq 35$ and $>35$ years respectively. The mean energy-adjusted reliability coefficients varied from 0.48 and 0.68 in participants aged $\leq 35$ and $>35$ years; the mean reliability in women was 0.60 (18). Trained dieticians asked participants to designate their intake frequency for each food item consumed during the previous 
year on a daily, weekly or monthly basis. Portion sizes of consumed foods reported in household measures were then converted to grammes. Mean daily intakes of energy and nutrient for each individual were calculated using the food composition table. Dietary TAC was estimated based on the oxygen radical absorbance capacity of selected foods reported by the nutrient data laboratory of the United States Department of Agriculture, and expressed as $\mu \mathrm{mol}$ of Trolox equivalents per $100 \mathrm{~g}$ offoods $(\mu \mathrm{molTE} / 100$ g) (19).

\section{Statistical analysis}

Whole diet TAC as well as TAC for individual food groups was assigned as quartiles based on their 25th, 50th and 75 th percentile values. Differences in general characteristics across quartiles of dietary TAC were compared using analysis of variance for continuous variables and the chi-squared test for categorical variables. Mean dietary intakes of participants were compared across quartile categories of dietary TAC using the general linear model with adjustment for age (years, continuous) and energy intakes ( $\mathrm{kcal} / \mathrm{day})$. The odds ratio (OR) and $95 \%$ confidence interval (CI) of breast cancer in each quartile of total TAC as well as TAC for different food groups was determined by multivariable logistic regression models with adjustment for potential confounding variables. The following potential confounders were included in the final multivariate logistic regression models: age (years); BMI $\left(\mathrm{kg} / \mathrm{m}^{2}\right)$; educational level (years); occupation (housekeeper, employee, retired); age at menarche (years); marital status (not married, married, divorced, widowed); age at first pregnancy (years); number of full pregnancies; menopause status (yes/no); family history of breast cancer (yes/no); use of oral contraceptive pills (yes/no); life satisfaction (yes/ no/partly); physical activity (METs $\mathrm{h} /$ week); energy intake (kcal/day); and energy density of diet $(\mathrm{kcal} / 100 \mathrm{~g}$ foods).

To assess the overall trends of ORs across increasing quartiles of TAC, the median of each quartile was used as a continuous variable in logistic regression models. Statistical analysis was performed using SPSS, version 16.0. A $P$-value $<0.05$ was used to indicate statistical significance.

\section{Results}

\section{Background data}

The mean ages of participants were 46.2 (SD 8.9) years and 45.9 (SD 9.4) years in the case and control groups respectively. The mean of age at menarche was significantly lower and the mean of age at first pregnancy was significantly higher in cases as compared with controls $(P<0.01)$. The use of tobacco and oral contraceptives was significantly higher, and while life satisfaction was significantly lower in women with diagnosed breast cancer as compared with the controls $(P<0.05)$. Significantly more cases (25.1\%) than controls (14.2\%) had a family history of breast cancer (Table 1). There were no significant differences, however, in BMI, physical activity, energy intake, diabetes prevalence, menopause status, educational level, occupation or marital status between the 2 groups (Table 1).

The mean dietary TAC of women with breast cancer was 1564 (SD 452) umolTE/ $100 \mathrm{~g}$ of foods and this was not statistically different from that of the controls $[1584$ (SD 600) $\mu \mathrm{molTE} / 100 \mathrm{~g}]$.

\begin{tabular}{|c|c|c|c|}
\hline Variable & $\begin{array}{c}\text { Cases } \\
(n=100)\end{array}$ & $\begin{array}{l}\text { Controls } \\
(n=175)\end{array}$ & $P$-value ${ }^{a}$ \\
\hline Age [mean (SD) years] & $46.2(9.3)$ & $45.9(9.4)$ & 0.13 \\
\hline Physical activity [mean (SD) METs h/week] & $38.8(4.1)$ & $38.5(4.5)$ & 0.32 \\
\hline Weight [mean (SD) kg] & $72.0(11.7)$ & $73.1(12.4)$ & 0.51 \\
\hline Body mass index [mean (SD) $\left.\mathrm{kg} / \mathrm{m}^{2}\right]$ & $29.6(4.5)$ & $29.3(4.1)$ & 0.79 \\
\hline Age at menarche [mean (SD) years] & $13.9(1.6)$ & $13.3(1.5)$ & 0.01 \\
\hline Family history of breast cancer (\%) & 25.0 & 18.0 & 0.18 \\
\hline History of diabetes (\%) & 13.1 & 13.2 & 0.98 \\
\hline Current smoking (\%) & 9.3 & 0.6 & 0.01 \\
\hline \multicolumn{4}{|l|}{ Occupation (\%) } \\
\hline Housekeeper & 72.0 & 77.0 & 0.31 \\
\hline Employee & 22.0 & 26.6 & 0.25 \\
\hline Retired & 6.0 & 2.4 & 0.14 \\
\hline Life satisfaction (\%) & 62.0 & 87.0 & 0.02 \\
\hline Menopause (\%) & 37.0 & 36.8 & 0.99 \\
\hline
\end{tabular}

alndependent t-test or Mann-Whitney test.

$S D=$ standard deviation; $n=$ number of women; $M E T s=$ metabolic equivalents. 


\section{Dietary TAC across quartiles}

The characteristics of the total study participants across quartile categories of dietary TAC are shown in Table 2 . There were no significant differences in age, physical activity, weight, BMI and other characteristics of the participants across quartiles of TAC.

Dietary intakes of energy, energy density, dietary TAC and dietary intake of food groups across quartile categories of TAC are shown in Table 3. Dietary energy intake (kcal/day) decreased significantly across increasing dietary TAC ( $P$ for trend $<0.001$ ), while dietary energy density (kcal/100 g of foods) was constant. Dietary TAC was 1.8 times higher in the 4th quartile compared with the 1st quartile [2061 (SD 37) versus 1151 (SD 37) $\mu \mathrm{molTE} / 100 \mathrm{~g}$ of foods] $(P<$ 0.01 ). Compared with the 1 st quartile categories of TAC, consumption of fruits, legumes, nuts, tea and coffee, as well as phytochemical-rich foods was significantly higher in the 4th quartile of TAC, while vegetable intake was significantly lower.

\section{Regression models}

The OR and 95\% CI of breast cancer across quartiles of dietary TAC are presented in Table 4. After adjustment for potential confounding variables, a non-significant inverse association was observed between dietary TAC and breast cancer risk. When multiple logistic regression models were conducted based on TAC of individual food groups, we observed that a higher TAC of fruits and vegetables consumed was accompanied by a significant decreased risk of breast cancer ( $P$ for trend < $0.05)$. Higher TAC consumption from fruits $>2030$ ( $\mu \mathrm{molTE} / 100 \mathrm{~g}$ of fruits) decreased the odds of breast cancer more than $80 \%$ (OR 0.16; 95\% CI: 0.06-0.44). Women who had a TAC consumption from vegetables $>617$ ( $\mu$ molTE/ $100 \mathrm{~g}$ of vegetables) also had significant lower odds of breast cancer in the 3rd quartile (OR 0.32; 95\% CI: $0.15-0.71)$ and 4th quartile category (OR 0.29; 95\% CI: 0.13-0.68). The TAC from other food groups showed no similar effects.

The OR and 95\% CI of breast cancer across quartiles of dietary TAC are presented in Table 4. After adjustment for potential confounding variables, a non-significant inverse association was observed between dietary TAC and breast cancer risk.
Multiple logistic regression models were also conducted based on TAC of individual food groups; TAC of fruits was not associated with the risk of breast cancer in the first model but after additional adjustment for potential confounders in the second, third and fourth models, we observed that a higher TAC of fruits was accompanied by a significant decreased risk of breast cancer $(P$ for trend $<0.05)$. Higher TAC consumption from fruits $>2030$ ( $\mu$ molTE/100 g of fruits) decreased the odds of breast cancer more than $80 \%$ (OR 0.16; 95\% CI: 0.06-0.44). There was no significant association between TAC of vegetables and breast cancer risk in the first, second and third models; after additional adjustment for menopause status, family history of breast cancer, physical activity, energy intake and energy density of diet. In the fourth model, women who had a TAC consumption from vegetables $>617$ ( $\mu$ molTE/100 g of vegetables) also had significant lower odds of breast cancer in the 3rd quartile (OR 0.32; 95\% CI: 0.15-0.71) and 4th quartile category (OR 0.29; 95\% CI: 0.13-0.68). The TAC from other food groups showed no similar effects.

\begin{tabular}{|c|c|c|c|c|}
\hline \multicolumn{5}{|c|}{$\begin{array}{l}\text { Table } 2 \text { Characteristics of total participants (breast cancer cases and controls) across quartile (Q) categories of dietary total } \\
\text { antioxidant capacity (TAC) }\end{array}$} \\
\hline \multirow[t]{3}{*}{ Variable } & Q1 & Q2 & Q3 & Q4 \\
\hline & $\begin{array}{l}\quad<1327 \\
\text { umolTE/100 g }\end{array}$ & $\begin{array}{c}\text { 1327-1525 } \\
\mu \mathrm{molTE} / 100 \mathrm{~g}\end{array}$ & $\begin{array}{l}\text { 1526-1704 } \\
\mu \mathrm{molTE} / 100 \mathrm{~g}\end{array}$ & $\begin{array}{c}>1704 \\
\mu \mathrm{molTE} / 100 \mathrm{~g}\end{array}$ \\
\hline & $(n=68)$ & $(n=69)$ & $(n=69)$ & $(n=68)$ \\
\hline Age [mean (SD) years] & $46.2(9.0)$ & $44.3(9.2)$ & $46.5(9.3)$ & $47.2(9.0)$ \\
\hline Physical activity [mean (SD) METs h/week] & $38.7(0.5)$ & $38.1(0.5)$ & $39.8(0.5)$ & $37.7(0.5)$ \\
\hline Weight $[\text { mean }(\mathrm{SD}) \mathrm{kg}]^{\mathrm{a}}$ & $72.8(1.7)$ & $72.2(1.7)$ & $73.1(1.7)$ & $71.5(1.7)$ \\
\hline Body mass index [mean $\left.(\mathrm{SD}) \mathrm{kg} / \mathrm{m}^{2}\right]^{\mathrm{a}}$ & $29.9(0.6)$ & $30.2(0.6)$ & $29.1(0.6)$ & $28.5(0.6)$ \\
\hline Menopausal (\%) & 32.4 & 33.3 & 39.1 & 42.6 \\
\hline Smoking (\%) & 0.0 & 5.8 & 2.9 & 5.9 \\
\hline Prevalence of diabetes (\%) & 17.6 & 14.5 & 7.2 & 13.2 \\
\hline Age at menarche [mean (SD) years] & $13.6(1.6)$ & $13.8(1.6)$ & $13.6(1.7)$ & $13.8(1.4)$ \\
\hline Age at menopause [mean (SD) years] & $49.1(5.1)$ & $45.5(4.4)$ & $48.6(3.8)$ & $48.3(5.0)$ \\
\hline Family history of breast cancer (\%) & 17.6 & 17.4 & 13.0 & 25.0 \\
\hline
\end{tabular}

No significant differences were found between quartiles, using analysis of variance or general linear model (with adjustment for age) to compare continuous variables and chi-squared test for categorical variables.

${ }^{a}$ Age-adjusted means.

$S D=$ standard deviation; $n=$ number of women; METs = metabolic equivalents. 


\begin{tabular}{|c|c|c|c|c|}
\hline \multirow[t]{4}{*}{ Variable } & Q1 & Q2 & Q3 & Q4 \\
\hline & $\begin{array}{c}\quad<1327 \\
\mu \mathrm{molTE} / 100 \mathrm{~g}\end{array}$ & $\begin{array}{c}1327-1525 \\
\mu \mathrm{molTE} / 100 \mathrm{~g}\end{array}$ & $\begin{array}{c}1526-1704 \\
\mu \mathrm{molTE} / 100 \mathrm{~g}\end{array}$ & $\begin{array}{c}>1704 \\
\mu \mathrm{molTE} / 100 \mathrm{~g}\end{array}$ \\
\hline & Mean $(\mathrm{SE})^{\mathrm{a}}$ & Mean $(\mathrm{SE})^{\mathrm{a}}$ & Mean $(\mathrm{SE})^{\mathrm{a}}$ & $\operatorname{Mean}(\mathrm{SE})^{\mathrm{a}}$ \\
\hline & $(n=68)$ & $(n=69)$ & $(n=69)$ & $(n=68)$ \\
\hline Energy (kcal/day) & 2846 (119) & $2653(118)$ & 2687 (118) & $2575(119)^{* *}$ \\
\hline Energy density (kcal/100 g of foods) & $126(3.2)$ & $119(3.2)$ & $112(3.2)$ & $128(3.2)$ \\
\hline Dietary TAC ( $\mu$ molTE/100 g of foods) & $1151(37)$ & $1434(37)$ & $1611(37)$ & $2061(37)^{* *}$ \\
\hline Fruits (g/day) & $481(35)$ & $621(35)$ & $611(35)$ & $596(35)^{* *}$ \\
\hline Vegetables (g/day) & $531(36)$ & $505(36)$ & $549(36)$ & $413(36)^{* *}$ \\
\hline Whole grains (g/day) & $152(10.7)$ & $158(10.6)$ & $161(10.6)$ & $138(10.7)$ \\
\hline Dairy (g/day) & $441(36.5)$ & $503(36.1)$ & $573(36.1)$ & $458(36.8)$ \\
\hline Legumes (g/day) & $37.1(5.1)$ & $44.9(5.1)$ & $51.6(5.1)$ & $50.2(5.1)^{* *}$ \\
\hline Nuts (g/day) & $10.0(1.8)$ & $13.8(1.8)$ & $12.5(1.7)$ & $17.3(1.8)$ \\
\hline Tea and coffee (cup/day) & $1.4(0.3)$ & $2.4(0.3)$ & $3.3(0.3)$ & $5.0(0.3)^{* *}$ \\
\hline $\begin{array}{l}\text { Phytochemical-rich foods (\% of total } \\
\text { foods) }\end{array}$ & $53.7(1.1)$ & $59.0(1.1)$ & $62.2(1.1)$ & $66.1(1.1)^{* *}$ \\
\hline
\end{tabular}

${ }^{* *} P<0.01$, using general linear model to compare the dietary intakes of participants across quartiles of dietary TAC. ${ }^{a}$ Adjusted for age and energy intake.

$S E=$ standard error of the mean; $n=$ number of women.

\section{Discussion}

The most important finding of this study was an inverse non-significant association between dietary TAC and breast cancer risk. Moreover a significantly higher odds of breast cancer was observed with an increased TAC of fruits and vegetables. Previous epidemiological studies have evaluated the association of dietary antioxidants and serum antioxidant levels with breast cancer risk $(10,11)$ but, to our knowledge, dietary TAC in relation to breast cancer risk has not yet been investigated.

There is a common hypothesis that oxidative stress and oxidative products as well as low serum levels of antioxidants and low intake of dietary antioxidants could affect breast cancer risk in women $(10,11,20,21)$. However, the results from prospective and case-control studies are inconsistent and current data do not provide a clear association of antioxidant status and breast cancer risk. In a cohort study, no significant association was observed between breast cancer risk and serum levels of antioxidants - including lycopene, lutein, xanthine, $\beta$-cryptoxanthin, $\alpha$ - and $\beta$-carotene, retinol, $\alpha$-tocopherol and selenium - after 9.5 years' follow-up (10). In another prospective study, the median concentrations of $\beta$-carotene, lycopene and total carotene were significantly lower in women with diagnosed breast cancer, and a non-significant decreased risk of breast cancer was observed in women who had higher serum levels of antioxidants after 20 years' follow-up (11). A prospective cohort of Swedish women found no overall association between dietary intake of ascorbic acid, beta-carotene, retinol or vitamin $\mathrm{E}$ and breast cancer incidence, while higher consumption of high ascorbic acid foods had preventive effects but only in overweight women (20). A case-control study on Malaysian women showed that poor antioxidant status, as indicated by low plasma vitamin A, higher levels of malondialdehyde as an indicator of oxidative stress and lower intake of dietary antioxidants including vitamin $\mathrm{A}, \mathrm{E}$ and selenium, was associated with increased breast cancer risk (21). Recently, Aune et al. conducted a systematic review and meta-analysis of prospective studies of dietary intake of carotenoids and breast cancer risk and reported that only intake of $\beta$-carotene was associated with a decreased breast cancer risk (RR 0.95; 95\% CI: 0.91-0.99) (22). To our knowledge, studies investigated the association of dietary antioxidant and breast cancer risk are mainly limited to some particular antioxidants including carotenoids, vitamin C, E, A and selenium, while there are various other micronutrients and bioactive phytochemicals with antioxidative activity in foods. Therefore, an assessment of the TAC of the whole diet and food groups in relation to breast cancer risk can lead to more reliable results.

Several mechanisms have been proposed to explain the association between oxidative stress, antioxidant status and breast cancer risk. There is a common hypothesis that oxidative stress is involved in malignant processes in the breast. Increased oxidative stress and over-production of free radicals that 


\begin{tabular}{|c|c|c|c|c|c|}
\hline Food group/model ${ }^{a}$ & & Q1 & Q2 & Q3 & Q4 \\
\hline \multicolumn{6}{|l|}{ Total diet } \\
\hline TAC ( $\mu$ molTE/100 $\mathrm{g}$ food) & & $<1327$ & 1327-1525 & 1526-1704 & $>1704$ \\
\hline \multicolumn{6}{|l|}{ Breast cancer risk [OR $(95 \% \mathrm{CI})]$} \\
\hline Model 1 & 1 & & $1.36(0.68-2.71)$ & $1.32(0.66-2.62)$ & $0.65(0.31-1.34)$ \\
\hline Model 2 & 1 & & $1.14(0.49-2.65)$ & $0.98(0.41-2.33)$ & $0.57(0.24-1.36)$ \\
\hline Model 3 & 1 & & $1.16(0.43-2.57)$ & $1.01(0.42-2.36)$ & $0.45(0.18-1.21)$ \\
\hline Model 4 & 1 & & $0.67(0.12-2.81)$ & $0.59(0.17-2.15)$ & $0.43(0.11-1.12)$ \\
\hline \multicolumn{6}{|l|}{ Fruits } \\
\hline TAC ( $\mu$ molTE/100 g fruit) & & $<1619$ & $1619-1718$ & 1819-2030 & $>2030$ \\
\hline \multicolumn{6}{|l|}{ Breast cancer risk [OR $(95 \% \mathrm{CI})]$} \\
\hline Model 1 & 1 & & $0.91(0.45-1.82)$ & $0.66(0.31-1.41)$ & $0.29(0.10-0.84)$ \\
\hline Model 2 & 1 & & $0.92(0.47-1.81)$ & $0.68(0.34-1.34)$ & $0.31(0.14-0.66)^{* *}$ \\
\hline Model 3 & 1 & & $0.94(0.47-1.89)$ & $0.71(0.36-1.43)$ & $0.28(0.13-0.62)^{* *}$ \\
\hline Model 4 & 1 & & $0.78(0.34-1.82)$ & $0.48(0.21-1.11)$ & $0.16(0.06-0.44)^{* *}$ \\
\hline \multicolumn{6}{|l|}{ Vegetables } \\
\hline TAC ( $\mu$ molTE/100 g vegetables) & & $<546$ & $546-616$ & $617-682$ & $>682$ \\
\hline \multicolumn{6}{|l|}{ Breast cancer risk [OR $(95 \% \mathrm{CI})]$} \\
\hline Model 1 & 1 & & $1.140 .17-3.71)$ & $0.61(0.13-2.71)$ & $0.37(0.15-1.23)$ \\
\hline Model 2 & 1 & & $0.86(0.44-1.70)$ & $0.59(0.35-1.18)$ & $0.53(0.34-1.11)$ \\
\hline Model 3 & 1 & & $0.51(0.12-2.10)$ & $0.54(0.17-1.72)$ & $0.55(0.21-1.42)$ \\
\hline Model 4 & 1 & & $0.66(0.33-1.36)$ & $0.32(0.15-0.71)$ & $0.29(0.13-0.68)^{* *}$ \\
\hline \multicolumn{6}{|l|}{ Legumes } \\
\hline TAC ( $\mu$ molTE/100 g legumes) & & $<386$ & $386-468$ & $469-534$ & $>534$ \\
\hline \multicolumn{6}{|l|}{ Breast cancer risk [OR $(95 \% \mathrm{CI})]$} \\
\hline Model 1 & 1 & & $1.81(0.88-3.71)$ & $0.96(0.42-2.19)$ & $0.67(0.19-2.40)$ \\
\hline Model 2 & 1 & & $1.14(0.52-2.52)$ & $0.54(0.22-1.29)$ & $0.39(0.11-1.46)$ \\
\hline Model 3 & 1 & & $1.12(0.50-2.49)$ & $0.53(0.22-1.27)$ & $0.39(0.10-1.44)$ \\
\hline Model 4 & 1 & & $1.16(0.52-2.56)$ & $0.56(0.23-1.34)$ & $0.39(0.10-1.34)$ \\
\hline
\end{tabular}

${ }^{a}$ Multivariable logistic regression models were used with adjustment of potential confounders. Model 1: adjusted for age (years); Model 2: additional adjustment for age at menarche (years), age at first pregnancy (years), number of full pregnancies, smoking (yes/no), use of oral contraceptives (yes/no) and use of brassiere per day (< $12 \mathrm{~h} />12 \mathrm{~h}$ ); Model 3: additional adjustment for body mass index $\left(\mathrm{kg} / \mathrm{m}^{2}\right)$ and life satisfaction (yes/no/partly); Model 4: additional adjustment for menopause status (yes/no), family history of breast cancer (yes/no), physical activity (METs $\mathrm{h} /$ week), energy intake ( $\mathrm{kcal} /$ day), and energy density of the diet ( $\mathrm{kcal} / \mathrm{iO0} \mathrm{g}$ offoods).

${ }^{* *} P<0.01$, using the median of TAC for each quartile as a continuous variable to assess the overall trends of OR across quartile categories of dietary TAC. $O R=$ odds ratio; $C l=$ confidence interval; $n=$ number of women.

induces metabolic and inflammatory processes can lead to DNA damage, initiation of programmed cell death, activation of several proto-oncogenes and mutations of tumour suppressor genes that have critical roles in mammary carcinogenesis (23-25). Some exogenous and endogenous factors have important roles in modifying these oxidative damage. Enzymatic (thioredoxin reductase, superoxide dismutase, catalase and gluthathione peroxidase) and nonenzymatic (glutathione, antioxidant vitamins and minerals, flavonoids) antioxidant defence systems, as well as higher levels of plasma TAC, were found to be associated with reduced risk of breast cancer (26-28). Since intakes of antioxidants and antioxidantrich foods are directly related to the status of the antioxidant defence system, dietary intake of antioxidants may be considered as a main dietary factor that could modify the risk of breast cancer.

Studies show that the Mediterranean diet and other Mediterranean-type dietary patterns rich in fruits, vegetables, olive oil, legumes, whole grains, fish and low-fat dairy products have higher antioxidant load and are related to higher $\operatorname{TAC}(29,30)$; these dietary patterns are also considered as protective against the development of cancer (31). Modifying antioxidant intake by selecting foods based on their TAC could lead to a decreased risk of chronic diseases such as cancer $(32,33)$. So, beyond the common recommendations regarding adherence to Mediterranean-style dietary 
patterns, selection of food items with a higher antioxidant load should also be recommended.

The small sample size and the case-control design can be considered as weaknesses of this study. However, there were some strengths of this study, including the use of a validated semiquantitative FFQ for assessment of dietary intake, using multiple logistic regression models with adjustment of several confounding variables, and considering dietary TAC instead of single dietary antioxidants in relation to breast cancer risk.

Based on the findings from this study and other previous investigations, diets high in antioxidant-rich foods especially fruits and vegetables, whole grains, nuts, legumes and other plant-based foods is recommended to reduce the risk of cancer. Among the various food groups, higher TAC levels have been reported in nuts (especially walnuts, pistachio and almonds), fruits (plums, blackberries blueberries, oranges, dates, figs, apples and grapes) and vegetables (broccoli, cabbage, potato, beet, spinach, lettuce and onion) and dried fruits (dried pears) (19). In this study, other than dietary TAC, we examined the association of antioxidant capacity of food groups including fruits, vegetables and legumes with breast cancer risk. Independent of other dietary factors and potential confounders, consumption of fruits and vegetables with higher antioxidant capacity had higher protective effects to decrease the odds of breast cancer. These findings suggested that food selection based on the TAC of foods may be an effective strategy to increase antioxidant intake and hence to modify the risk of cancer.

\section{Acknowledgements}

Funding: This study was funded by the National Nutrition and Food Technology Research Institute, Shahid Beheshti University of Medical Sciences, Tehran, Islamic Republic of Iran.

Competing interests: None declared.

\section{References}

1. Bray F, Ren JS, Masuyer E, Ferlay J. Global estimates of cancer prevalence for 27 sites in the adult population in 2008. Int J Cancer. 2013 Mar 1;132(5):1133-45. PMID:22752881

2. Bray F, McCarron P, Parkin DM. The changing global patterns of female breast cancer incidence and mortality. Breast Cancer Res. 2004;6(6):229-39. PMID:15535852

3. Mousavi SM, Montazeri A, Mohagheghi MA, Jarrahi AM, Harirchi I, Najafi $M$, et al. Breast cancer in Iran: an epidemiological review. Breast J. 2007 Jul-Aug;13(4):383-91. PMID:17593043

4. Mettlin C. Breast cancer risk factors. Contributions to planning breast cancer control. Cancer. 1992 Apr 1;69(7) Suppl:1904-10. PMID:1544089

5. Gross RE. Breast cancer: risk factors, screening, and prevention. Semin Oncol Nurs. 2000 Aug;16(3):176-84. PMID:10967790

6. Lee SM, Park JH, Park HJ. Breast cancer risk factors in Korean women: a literature review. Int Nurs Rev. 2008 Sep;55(3):3559. PMID:19522954

7. Holmes MD, Willett WC. Does diet affect breast cancer risk? Breast Cancer Res. 2004;6(4):170-8. PMID:15217490

8. Frei B. Efficacy of dietary antioxidants to prevent oxidative damage and inhibit chronic disease. J utr. 2004 Nov;134(11):3196S8S. PMID:15514305

9. Mayne ST. Antioxidant nutrients and chronic disease: use of biomarkers of exposure and oxidative stress status in epidemiologic research. J Nutr. 2003 Mar;133 Suppl 3:933S-40S. PMID:12612179

10. Dorgan JF, Sowell A, Swanson CA, Potischman N, Miller $\mathrm{R}$, Schussler N, et al. Relationships of serum carotenoids, retinol, alpha-tocopherol, and selenium with breast cancer risk: results from a prospective study in Columbia, Missouri (United States). Cancer Causes Control. 1998 Jan;9(1):89-97. PMID:9486468

11. Sato R, Helzlsouer KJ, Alberg AJ, Hoffman SC, Norkus EP, Comstock GW. Prospective study of carotenoids, tocopherols, and retinoid concentrations and the risk of breast cancer. Cancer Epidemiol Biomarkers Prev. 2002 May;11(5):451-7. PMID:12010859
12. Wu X, Gu L, Holden J, Haytowitz DB, Gebhardt SE, Beecher G, et al. Development of a database for total antioxidant capacity in foods: a preliminary study. J Food Compos Anal. 2004;17(34):407-22.

13. Puchau B, Zulet MA, de Echávarri AG, Hermsdorff HH, Martínez JA. Dietary total antioxidant capacity: a novel indicator of diet quality in healthy young adults. J Am Coll Nutr. 2009 Dec;28(6):648-56. PMID:20516264

14. Pellegrini N, Serafini M, Colombi B, Del Rio D, Salvatore $S$, Bianchi M, et al. Total antioxidant capacity of plant foods, beverages and oils consumed in Italy assessed by three different in vitro assays. J Nutr. 2003 Sep;133(9):2812-9. PMID:12949370

15. Hermsdorff HH, Puchau B, Volp AC, Barbosa KB, Bressan J, Zulet MÁ, et al. Dietary total antioxidant capacity is inversely related to central adiposity as well as to metabolic and oxidative stress markers in healthy young adults. Nutr Metab (Lond). 2011;8(1):59. PMID:21859453

16. Bahadoran Z, Golzarand M, Mirmiran P, Shiva N, Azizi F. Dietary total antioxidant capacity and the occurrence of metabolic syndrome and its components after a 3-year follow-up in adults: Tehran Lipid and Glucose Study. Nutr Metab (Lond). 2012;9(1):70. PMID:22849424

17. Kriska AM, Knowler WC, LaPorte RE, Drash AL, Wing RR, Blair $\mathrm{SN}$, et al. Development of questionnaire to examine relationship of physical activity and diabetes in Pima Indians. Diabetes Care. 1990 Apr;13(4):401-11. PMID:2318100

18. Mirmiran P, Esfahani FH, Mehrabi Y, Hedayati M, Azizi F. Reliability and relative validity of an FFQ for nutrients in the Tehran lipid and glucose study. Public Health Nutr. 2010 May;13(5):654-62. PMID:19807937

19. Haytowitz DB, Bhagwat S. USDA database for the oxygen radical absorbance capacity (ORAC) of selected foods. Release 2. Beltsville (MD): United States Department of Agriculture, Agricultural Research Service; 2010 (http://www.orac-info-portal. de/download/ORAC_R2.pdf, accessed 4 January 2015).

20. Michels KB, Holmberg L, Bergkvist L, Ljung H, Bruce A, Wolk A. Dietary antioxidant vitamins, retinol, and breast cancer incidence in a cohort of Swedish women. Int J Cancer. 2001 Feb 15;91(4):563-7. PMID:11251982 
21. Sharhar S, Normah H, Fatimah A, Fadilah RN, Rohi GA, Amin $\mathrm{I}$, et al. Antioxidant intake and status, and oxidative stress in relation to breast cancer risk: a case-control study. Asian Pac J Cancer Prev. 2008 Apr-Jun;9(2):343-9. PMID:18712988

22. Aune D, Chan DS, Vieira AR, Navarro Rosenblatt DA, Vieira R, Greenwood DC, et al. Dietary compared with blood concentrations of carotenoids and breast cancer risk: a systematic review and meta-analysis of prospective studies. Am J Clin Nutr. 2012 Aug;96(2):356-73. PMID:22760559

23. Kang DH. Oxidative stress, DNA damage, and breast cancer. AACN Clin Issues. 2002 Nov;13(4):540-9. PMID:12473916

24. Ambrosone CB. Oxidants and antioxidants in breast cancer. Antioxid Redox Signal. 2000 Winter;2(4):903-17. PMID:11213491

25. Oestergaard MZ, Tyrer J, Cebrian A, Shah M, Dunning AM, Ponder BA, et al. Interactions between genes involved in the antioxidant defence system and breast cancer risk. Br J Cancer. 2006 Aug 21;95(4):525-31. PMID:16868544

26. Ching S, Ingram D, Hahnel R, Beilby J, Rossi E. Serum levels of micronutrients, antioxidants and total antioxidant status predict risk of breast cancer in a case control study. J Nutr. 2002 Feb;132(2):303-6. PMID:11823595

27. Hong TK, Lee-Kim YC. Effects of retinoic acid isomers on apoptosis and enzymatic antioxidant system in human breast cancer cells. Nutr Res Pract. 2009 Summer;3(2):77-83. PMID:20016705
28. Kim MK, Ahn SH, Son BH, Sung MK. Plasma antioxidant concentration, not superoxide dismutase polymorphism, is associated with breast cancer risk in Korean women. Nutr Res. 2010 Oct;30(10):705-13. PMID:21056286

29. Pitsavos C, Panagiotakos DB, Tzima N, Chrysohoou C, Economou M, Zampelas A, et al. Adherence to the Mediterranean diet is associated with total antioxidant capacity in healthy adults: the ATTICA study. Am J Clin Nutr. 2005 Sep;82(3):6949. PMID:16155285

30. El-Sabban F. The antioxidant advantage of the Mediterranean diet in cardiovascular disease. Nutr Diet Suppl. 2014 6:35-40.

31. Giacosa A, Barale R, Bavaresco L, Gatenby P, Gerbi V, Janssens $\mathrm{J}$, et al. Cancer prevention in Europe: the Mediterranean diet as a protective choice. Eur J Cancer Prev. 2013 Jan;22(1):90-5. PMID:22644232

32. Valtueña S, Pellegrini N, Franzini L, Bianchi MA, Ardigò D, Del Rio D, et al. Food selection based on total antioxidant capacity can modify antioxidant intake, systemic inflammation, and liver function without altering markers of oxidative stress. Am J Clin Nutr. 2008 May;87(5):1290-7. PMID:18469252

33. Franzini L, Ardigò D, Valtueña S, Pellegrini N, Del Rio D, Bianchi MA, et al. Food selection based on high total antioxidant capacity improves endothelial function in a low cardiovascular risk population. Nutr Metab Cardiovasc Dis. 2012 Jan;22(1):507. PMID:20674303 